\title{
La corrida de toros en Cádiz (1765-1790): Anotación a un arbitrio
}

\section{FERNANDO PEREZ MULET}

El tránsito del siglo XVIII, sus últimas décadas, supone una transformación de la sociedad española que, al día de hoy, podemos considerar como un hecho incuestionable. Uno de tantos exponentes de dicho cambio lo podemos encontrar en la fiesta taurina, en la corrida para mayor concreción, espectáculo que, a poco, cristalizaría en una tejné y en un rito de la mano del torero, nuevo individuo, artista y héroe (1) y de un público que, paulatinamente, depuraba sus sentimientos hasta el punto de aceptar la codificación que imponen las :reglas del toreo. Los denuestos de los ilustrados y la adoración equívoca de artistas como Goya echarían el resto.

Lejos de incidir en tales consideraciones que, por más, cuentan con extensa bibliografía, acudimos a un aspecto o finalidad del festejo taurino en Cádiz, desde 1765 hasta el fin de siglo. Sin pretender una absoluta relación causa-efecto observamos cómo la ciudad compromete un número exacto de corridas de cara a unos fines comunes y de conservación de sus murallas con lo que, de resultas, por una periodicidad forzada y por una organización empresarial resultante, se contribuye a enraizar una afición en el lugar al igual que en el resto de las poblaciones próximas hasta llegar a Sevilla.

$Y$ es que, efectivamente, Cádiz, en cuanto plaza fuerte y primer puerto de la Península en tráfico y volumen de mercaderías, gozaba de unos arbitrios específicos con los que la local Real Junta de Fortificaciones podía proceder casi autónomamente a la construcción y mantenimiento de obras públicas relacionadas con su defensa, cuales murallas o defensas, y con el camino de la Real Isla de León, orgullo del Cádiz de O'Reilly (2), a la misma plaza (3).

En 1765, a consecuencia de importantes brechas ocasionadas por unos fuertes temporales de invierno en la muralla del Vendaval, actual Campo del Sur gaditano, se solicitó de S.M. la creación de nuevos arbitrios para su consiguiente reparación, petición que era contestada afirmativamente, en Real Cédula, por el

(1) GONZALEZ TROYANO, Alberto: "El Torero Héroe Literario". Madrid, 1988.

Vid. De la incidencia de la llustración dieciochesca y de los comienzos del Casticismo, pp. 83 y ss.

(2) ANTON SOLE, Pablo: El Cádiz del Conde de O’Reilly, en CADIZ EN LA CARRERA DE LAS INDIAS, Cádiz, 1967.p. 23.

(3) PONZ, Antonio: "Viaje de España". Madrid, 1792. tomo XVIII, pp 94 y 95.

DOI: http://dx.doi.org/10.25267/Trocadero.1995.i6.21 
Marqués de Esquilache (4). Pero en este caso lo que encontramos no es arbitrio o porcentaje más sobre determinado comercio, recreo o espectáculo (5) sino la concesión de 120 corridas a celebrar en el plazo de 10 años, a razón de 12 por año, y ello junto con el Asiento del Reparo de las Brechas de la Muralla del Bendaval (sic) (6): el ingreso de las mismas corridas sería el que sufragara los gastos ocasionados por la reparación de dicha defensa.

Toda una serie de cláusulas contractuales aseguraba tal concierto, acuerdo del que el asentista adjudicatario debería obtener, en cuanto beneficio propio, aparte los dedicados a la obra, siete mil quinientos reales de vellón, suma que, en 1765, importaba el beneficio que, por corridas contratadas con anterioridad, disfrutaba el Hospital de Mujeres (7). De igual forma, se estipulaba que se daría por su Ex. . las correspondientes providencias no solo para que en este año, no se executen otras fiestas, concedidas antes de abora, á reserva de las seis del Hospital de Mujeres por estar la Contrata Hecha del todo de ellas, y espirar en este año, sino para embarazar representándolo a S.M. cualquiera gracia de esta naturaleza que sin noticia de su Exª. pueda conseguirse, porque mayor Nümero de Fiestas, no solo podrá ser gravoso á el Común, sino que será éfectivamente perjudicial á quien tomare el Asiento de las Doce, que bán de convertirse en óbra tán del bien de este Pueblo y Servicio de S.M. (8).

Las espectativas del referido asiento no serian nimias si atendemos a la puja entre Antonio Allier, vecino de Madrid y asentista de la obra del Arrecife, apoderado por Bartolomé Antonio de Losada y Quiroga, regidor perpetuo de Cádiz, y Agustín de Erquicia, mercader y vecino de Cádiz, navarro de nacimiento, quien, tras su pliego de condiciones, mejorando económicamente la propuesta de Allier, se quedaba con dicho doble asiento (9) aun cuando, a la postre, no remataría las obras de reparación (10).

En la sucesión del mismo, pues Erquicia muere en 1768 (1769?) (11), encontramos sucesivamente a Allier, Juan de Mora y Melchor Conde y, finalmente, Juan de Mora y Antonio García Roldán, vecinos, que, especialmente Mora, actúan como empresarios de la plaza de toros en que se desarrollan los festejos (12).

(4) FERNANDEZ CANO, Víctor: "Las Defensas de Cádiz en la Edad Moderna". Sevilla, 1073. p. 187.

(5) Ibidem. vid. cap. XII, Las Murallas de Cádiz en el siglo XVIII. Los arbitrios., pp. 173 y ss.

(6) Archivo Histórico Provincial de Cádiz. Sección de Protocolos, Notaría 28, Libro 5899, Año 1765. (s.f.): Expediente fornado para Asiento del Reparo de las Brechas de la Muralla del Bendaval y Sobre la Rl. Concesión de los diez años de Toros á razón de doce Corridas en cada uno, cuio ingreso se destina pa. dbo. reparo.

(7) Ibidem.

(8) Ibidem.

(9) Ibidem. Propuesta de Agustín de Erquicia dirigida al Excmo. Sr. Presidente de la Real Junta de Fortificaciones.

(10) FERNANDEZ CANO, Víctor: ob. cit. p. 187.

(11) Archivo Histórico Provincial de Cádiz. Sec. Protocolos. Notaría 13, Libro 2556, fol 266. Testamento de Agustín de Erquicia en 19 de Agosto de 1768.

(12) A.H.P.C. Sec. Protoc. Notaría 28, Libros 5900 y 5901 (s.f) y Notaría 4, Libro 908, fol. 405: Declarazon y Manifestación de participación. en cierta empresa de toros becha entre Dn. Juan de Mora y Dn. Melcbor Conde. 1777, Mayo, día 17, en Cádiz. 
Las corridas, por tanto, evidentemente beneficiaban a unos y otros y, entrambos, al espectador gaditano. Un memorial elevado por el Cabildo gaditano a S.M. Carlos IV, a resultas de la: extraña Real Pragmática que prohibía las fiestas de toros, en noviembre de 1790 , reflejaba tal comunidad de intereses pues, como indica, el producto de los festejos de toros ha sido uno de los medios con que muchos años hă, se bán construido y conservado las Murallas de ésta Plaza. Lo crecido de éste arbitrio que ascendia en el tiempo de su extincion á más de 25 mil pesos anuales, y la insensibilidad con que el pueblo arrebatado de su afición contribuia a ésta cantidad, ba becho, que se juzgue siempre como uno de los medios más propios para atender á la Construcción y conservación de las Murallas...

...aūn que el Ayuntamiento conoce los útiles efectos de esta providencia (la antedicha Pragmática o suspensión) los vé malogrados en ésta Ciudad, pues permitiéndose las Corridas de Toros en la del Puerto, y Xerez, distantes poco de esta concurren $\vec{a}$ ellas todos los menestrales y artesanos de esta población, sufriendo el doble perjuicio ya de a la pérdida del tiempo, y ya del coste de los viajes...(13).

Era, un hecho evidente el enraizamiento de la afición en Cádiz, afición que, desde distintas fuentes, se recoge. González del Castillo lo refleja en su sainete $E l$ día de toros en Cádiz (14) o José Vargas Ponce en su negativa Disertación sobre las Corridas de Toros donde, al respecto de corridas en días laborables, se transforman en feriados tantos en número que en pueblos como Cádiz y Sevilla llegaría a casi un mes al año y se duplica al menos como notorio, porque el alboroto de estas fiestas hace perder al jornalero y menestral tantas hora antes y después de las consumidas mientras se celebran... (15).

No menos sensible a la perniciosidad del espectáculo fueron los Obispos Fray Tomás del Valle, Fray Juan Bautista Servera y Antonio de la Plaza, interesados por asegurar, en una sana ordenación de valores, instrucción cristiana en sus razonadas quejas a la celebración de las corridas en días festivos (16).

El espectáculo, por otra parte, cobraría caracteres míticos si acudimos a las repetidas estancias de los Romero, de Ronda, y Pepe "Hillo", de Sevilla, amén de otros matadores locales, más modernos, como el chiclanero Gerónimo José Cándido, ya" en 1804 (17).

No obstante, aunque no debía ser frecuente, por otro lado, Adolfo de Castro, aludiendo a una papeleta de la decimonovena corrida de 1787, refirió, aparte la intervención inicial de Pedro y Antonio Romero y de Juan Conde, de Vejer, la siguiente nota de la misma:

(13) Archivo Municipal de Cádiz. Actas Capitulares de Cádiz. Cabildo del 17 de noviembre de 1790, libro 145 , fol. 351.

(14) GONZALEZ DEL CASTILlo, Juan Ignacio: "el café de Cádiz y otros sainetes", (Edición de Carmen Bravo Villasante), Madrid, 1977. p. 93.

(15) VARGAS PONCE, José: "Disertación sobre las Corridas de Toros", Madrid, 1961 (La edición es de Julio F. Guillen Tato. La disertación es de 1807), p 215.

(16) ANTON SOLÉ, Pablo: La prohibición de las corridas de toros en días festivos y los obispos de Cádiz, en "Archivo Hispalense", n² 167, Sevilla, 1965, pp. 97 a 111.

(17) Carteles de 1804. El primero para las corridas del martes, 3; y miércoles, 4, de Abril, primera y segunda corrida del año. El segundo para la del sábado, 25, de Agosto, decimooctava del año (Colección privada. Cádiz). 
"Para que la tarde sea más completa y divertida, pasado que sea el sexto toro, entrarán las barcas cañoneras, las que darán vuelta alrededor de la plaza, harán una salva completa, después batirán un castillo que estará situado en medio de dicha plaza con su guarnición correspondiente, la que hará su defensa, y al fin quedará vencido y deshecho, y la tripulación de dichas cañoneras, desde éstas, rejonearán al toro con sus propios remos, y después lo matarán.

Esto, como se ve, era una clase de espectáculo desconocido de la generación presente" (18).

En cualquier caso, el espectáculo tampoco debió ser habitual en la plaza gaditana a tenor no sólo del pragmatismo o, en su caso, educación ilustrada de la ciudad, sino, andando el tiempo, de los carteles observados (19).

Si era un hecho que levantaban afición las repetidas lidias de los diestros Romero e Hillo, afición propagada por otros rincones del reino: en 1789, en abril, los regidores perpetuos y diputados del Cabildo para las corridas, de acuerdo con el Gobernador, deberían responder a la solicitud del Ayuntamiento de Badajoz de requerir la presencia de Pedro Romero con su quadrilla y confiaba de que la superior autoridad de V.E. se digne tener la bondad de allanarle para que se verifique la venida de dicho Romero a cuio efecto se bace el propio conductor de esta (misiva) (20).

De igual forma, la rivalidad existente entre Romero e Hillo, constante germen de espectáculo, contribuía al mismo como es notorio. Los contratos entre asentista de la plaza y torero, en función del posible emparejamiento, variarían en la obligación pecuniaria, según se desprende de sendas obligaciones y contratas formalizadas en marzo y octubre de 1778 entre Juan de Mora y Antonio García Roldán, por una parte, y "Josseph Delgado, alias, Hillo", por otra (21).

(18) CASTRO, Adolfo de: "Combates de toros en España y Francia", Madrid, (1889) pp. 99-101.

(19) Vid. nota 17. En cada tarde se lidiaban 10 toros. La única referencia colorista, muy habitual, alude en la de agosto a la siguiente nota:

"Con motivo de la celebriclad expresada (el "augusto nombre de la Reina Nuestra Señora") se empavesará la Plaza vistosamente; habrá en ella una numerosa vanda de músicos que contribuya, en los intermedios, á la diversión; estarán los caballos primorosamente enjaezados; y se procurará con esmero que en todo el servicio de la función reluzca la más brillante decencia”.

(20) Archivo Municipal de Cádiz. A.C.C. Cabildo del 25 de abril de 1789. fol 192.

(21) A.H.P.C. Sec. Protoc. Notaría 17. Libro 3844. fol. 95. Idem, Contrato y obligación en 6 de Marzo de 1778 en Cádiz. Pepe "Hillo" cobraría 1400 reales de vellón por corrida y su ayudante, Francisco Guillén, 800 , ambos pagaderos al término de la misma; igualmente, cada uno cobraría otros doce diarios desde que cada uno de ellos salga de su casa, llamados por los asentistas, basta el en que se concluyan las corridas de este año, y regresen a sus respectivos domicilios. Las cantidades enunciadas, aún en caso de cogida, lesión o muerte, se respetarían. En fol. 524, contrato de 24 de octubre de igual año: Que el dho Josseph Delgado servirá la plaza, por sí, como primera espada, y en el caso deqe. venga á acompañarle en el ejercicio Pedro Romero, deverá alternar con este, llevandola una tarde uno, y otra otro, en cuya recompensa los reunidos asentistas le darán al dbo. Jossepb Delgado mil rs. vel. por cada tarde. Siendo acompañado del Romero. Pero no verificándose la venida al fin insinuado o por otro accidente que no salga el Romero a la plaza, le abonaran al dbo. Hillo por cada una de las tardes en qe. se lidien toros, ocbenta psos. de quince rs., cuya paga se bará de bacer, luego que se concluya cada corrida en moneda de oro ó plata usual y corriente... 
La fortificación y conservación de la ciudad avanzó, sin solución de continuidad, hasta la Guerra de la Independencia. A partir de este momento podemos considerar cerrado un período de la historia gaditana. La continuidad de los arbitrios fue, pues, constante y, si cabe, en aumento (22). Al respecto del festejo taurino baste decir que los referidos carteles de 1804, a tenor del encabezamiento, manifiestan que EL REY NTRO. SOR. (QUE DIOS GUARDE) TIENE CONCEDIDAS A ESTA NOBILISIMA CIUDAD DE CADIZ Doscientas Corridas de Toros, Destinando Sus Productos A Las Reales Obras De Fortificación De La Plaza... (23).

Una plaza de toros, un coso poligonal, al estilo racional de las existentes en Andalucía (24), y de madera, fue el escenario en el mismo Campo del Sur de tales espectáculos. La plaza, "Hoyanca", casi cuadrada, con los ángulos achaflanados en cuatro lados menores, prácticamente surge en este momento, supliendo la multiplicidad de uso de las plazas abiertas gaditanas como la Real o la de San Antonio, donde anteriormente y sin esta periodicidad se habían celebrado festejos "de toros y muerte".

Aunque dicha plaza, el escenario apuntado, desaparecería con el tiempo hay licencia para aceptar que, en la parte que le toca, el festejo taurino tuvo algo que ver en la configuración de la fisonomía de la ciudad y ésta, como contrapartida, en el apogeo de la Fiesta entre sus vecinos.

Esta documentación, gentilmente ofrecida por D. Manuel Ravina Martín, Director del Archivo Histórico Provincial de Cádiz, ha sido publicada con otras en un adelanto de su investigación taurina. Vid. RAVINA MARTIN, MANUEL: Documentos taurinos en el Archivo Histórico Provincial de Cádiz (Avance de un catálogo), en "Revista de Estudios Taurinos", no 2, Sevilla, 1995, pp. 95-124.

(22) FERNANDEZ CANO, ob. cit. p. 183

(23) Vid. nota 17.

(24) BONET CORREA, Antonio: "Morfología y Ciudad. Urbanismo y arquitectura en España durante el Antiguo Régimén", Barcelona, 1978. Vid. La antigua Plaza de Toros de Valladolid, boy Cuartel de la Guardia Civil en pp. 143 y ss. 